\title{
Editorial
}

\section{Establishment of National Institute of Neurosciences \& Hospital: Bangladesh Perspective}

\author{
Quazi Deen Mohammad \\ Director \& Professor of Neurology, National Instittue of Neuroscinces and Hospital, Sher-E-Bangla Nagar, Agargaon, \\ Dhaka-1207, Bangladesh; Email: nins_hospital@yahoo.com
}

Bangladesh is a small densely populated country facing problems of communicable and non-communicable diseases. By the enormous efforts of Government and nonGovernment agencies with the help of world health organization (WHO) communicable diseases have been kept under control or some of them are eradicated; however, at the same time there is emergence of noncommunicable diseases (NCD) like diabetes mellitus, hypertension, ischaemic heart disease, cancer and stroke which are partly due to increase of expectancy of life as well as sedentary life style faulty food habit and others. All the important NCDs are prevalent in the country of which stroke demands spinal attention due to increase morbidity and mortality.

Stroke is one of the commonest neurological diseases that affect a significant number of the population in Bangladesh. Furthermore, there are other neurological diseases like head injury, brain tumour, epilepsy, meningitis, encephalitis and many more. Therefore a large number of patients admitted everyday into the hospital for treatment purposes. However, due to limited facilities of intensive care unit (ICU), hospital bed, and interventional neurology in the hospital these cause a great burden to the health sector of Bangladesh. In addition to that lack of advance technologies cause delayed diagnosis leading to influence the patients to go to abroad for better treatment. Therefore huge amount of foreign currencies are drained every year. Keeping all these things in mind the member of the society of Neurosciences have decided to establish National Institute of Neurosciences (NINS) in Bangladesh with the vision of making this Institute as the centre of excellence not only in this country but also for others. Ultimately the present NINS is the outcome of this effort.

Currently this is the only referral tertiary care Neurology hospital in Bangladesh dealing with neurological as well as neurosurgical diseases. The current objective of NINS is to provide treatment to different neurological and neurosurgical cases in this country and to do the scientific research works as well as to collaborate with the other parallel institutes in abroad. It is a matter of pride that the institute has started functioning from September 2012 with OPD, IPD, emergency, ICU services as well as wellequipped operation theater (OT) facilities.

There are more than 15 departments related to neurological and neurosurgical diseases with more than 150 faculty members. Neurophysiology and interventional neurology are the two newly established departments which have been established first time ever in Bangladesh at public health sector. The NINS should be the centre of excellence in the country in near future where there should be the provision for one step services for the neurological cases. By this time the Institute has got its working life with the presence of 800 to 1000 patients in OPD everyday and 8 to 10 minor to major operation and the work in the paraclinical departments. The people by the time loved it and the Instittue feels proud to serve the sufferings of the human.

[J Natl Inst Neurosci Bangladesh, 2015;1(1):1] 